\title{
INMIGRACIÓN, ETNICIDAD Y XENOFOBIA EN LA ARGENTINA: LA MASACRE DE TANDIL*
}

POR

CLARA E. LIDA

El Colegio de México

\begin{abstract}
El milenarismo y la xenofobia se aunaron en la revuelta gaucha en Tandil (Argentina), en 1872. En los orígenes de este movimiento están las páginas regionales y provinciales contra el centralismo de Buenos Aires, el cercamiento de tierras que amenazaban la ganadería itinerante tradicional, el crecimiento del capitalismo agroexportador a expensas de los mercados y comerciantes internos y el comienzo decidido de la inmigración europea masiva. Instigados por los grupos sociales y provinciales contrarios a estos desarrollos, el imaginario gaucho interpreta que sólo el exterminio de los extranjeros permitiría la realización de la utopía milenarista en las pampas argentinas.
\end{abstract}

En 1861, con el triunfo del general Bartolomé Mitre en la batalla de Pavón sobre las fuerzas confederadas argentinas, se selló definitivamente la hegemonía porteña de Buenos Aires. La década que se inició entonces se caracterizó, a grandes trazos, por el apogeo de los intereses agropecuarios y comerciales del litoral del Plata, apoyados por inversionistas extranjeros, especialmente ingleses. El desarrollo de una sólida red económica era imprescindible para el buen éxito de una oligarquía terrateniente emprendedora que basaba su poder en una modernización técnica creciente y en la incorporación de las tierras todavía marginadas. Este proceso se aceleró con el ímpetu del

\footnotetext{
* Este texto es parte del libro de próxima aparición, Inmigración y exilio (México: El Colegio de México-Siglo XXI Editores). Una versión muy preliminar de este artículo apareció en Clara E. LIDA, "La masacre de Tandil. Inmigración y milenarismo en la Argentina en el último tercio del siglo XIX", en Historia $66,30,1978$, pp. 74-80.
} 
tendido ferroviario y telegráfico, el desarrollo de puertos y vías fluviales y el rápido poblamiento y explotación de zonas hasta entonces casi vírgenes.

Para un país de casi tres millones de kilómetros cuadrados que al mediar el siglo apenas alcanzaba el millón trescientos mil habitantes, la expansión de las fronteras agrarias gracias a las triunfantes campañas contra los indios implicó forzosamente la búsqueda de pobladores más allá de los límites nacionales. Esta política poblacionista fue respaldada por muchos de los ideólogos del desarrollo argentino que, como Domingo F. Sarmiento y Juan B. Alberdi, creyeron en la malthusiana fórmula de "gobernar es poblar". Tal actitud se reflejó en el Preámbulo de la Constitución liberal de 1853, que garantizaba la libertad "para todos los hombres del mundo que quieran habitar el suelo argentino", aunque su carácter universalista se limite en el articulo $25 \mathrm{al}$ fomento de "la inmigración europea", restringiendo así el ingreso de pobladores que provinieran de otros continentes.

En 1869, fecha del primer censo nacional bajo la presidencia de Sarmiento (1868-1874), la Argentina aparece ya con una población de 1736923 habitantes, sin contar los 93291 indios de las fronteras y los 6276 soldados destacados en el Ejército del Paraguay, durante la guerra en el norte. La población seguía siendo escasa, con un aumento de sólo unas 500000 personas en poco más de diez años, pero el censo revela un $13.8 \%$ de extranjeros por argentinos nativos, es decir unas 210300 personas. En el siguiente cuarto de siglo estas cifras se multiplicaron aceleradamente hasta representar en 1895 el 34\%, es decir, un total de 1004500 extranjeros, lo cual corrobora ampliamente la magnitud e intensidad de la política poblacionista argentina en el último tercio del siglo XIX.

\section{LA INMIGRACION Y SUS EFECTOS}

Aunque originalmente uno de los propósitos fundamentales de las políticas migratorias de la Argentina al atraer extranjeros era llevar colonos para poblar y trabajar las tierras recientemente abiertas a la explotación rural, en la práctica la inmigración europea en las tierras del Plata se distribuyó de modo muy distinto al planeado inicialmente. La población urbana, que en 1869 era del $27 \%$, en 1895 pasó al 37\%, proporción que cobra aún más relieve si la refe-

R. I., 1998, n. ${ }^{\circ} 214$ 
rimos a la ciudad de Buenos Aires, cuya población de 85000 habitantes en 1852 pasaba del medio millón en 1889. En 1895, mientras solamente el $14 \%$ de los argentinos nativos habitaban en la capital, el $39 \%$ de los extranjeros vivía en Buenos Aires. Este carácter cosmopolita despuntaba ya en 1869, cuando la ciudad porteña, aunque todavía pequeña, aparecía ya como un centro de inmigración donde una de cada dos personas había nacido del otro lado del Atlántico ${ }^{1}$.

Mientras las ciudades se poblaban y urbanizaban, el campo también sufría cambios radicales. Los inmigrantes que debían poblar las pampas $\mathrm{y}$, con sus tradiciones de labriegos y pastores sedentarios, ayudar a poner fin al tradicional pastoreo itinerante de los gauchos en las grandes extensiones abiertas, contribuyeron poco a transformar el régimen de la tierra, que en vez de permitir la formación de pequeños y medianos propietarios, consolidó el latifundio en manos de poderosos grupos. En cambio, si la inmigración no logró acelerar el desarrollo de la pequeña y mediana propiedad, como pretendían los partidarios de la colonización, sí incidió decisivamente en el panorama social, cultural y técnico de las regiones en las que se asentaron los extranjeros, pues en los años de 1880 las ocupaciones del $75 \%$ de los inmigrantes en su país de origen eran agropecuarias. La agricultura y la ganadería argentinas se sirvieron del inmigrante, ya que el gaucho, pastor por excelencia de rebaños y tropillas trashumantes, carecía de la preparación adecuada para las tareas agrícolas intensivas y para la cría de ganado sedentario, cuya carne era ya cotizada en los mercados internacionales. Así pues, en su mayoría, los extranjeros que se instalaron en el campo no solo no colmaron sus ansias de tierra sino que permanecieron sobre todo como arrendatarios o como peones asalariados en campos ajenos, a menudo enfrentados a lo que las élites porteñas habían dado en llamar la "barbarie gaucha".

\footnotetext{
1 Para las cifras y proporciones citadas véanse los siguientes censos, más significativos por las tendencias que marcan que por la exactitud de los números absolutos: Censo de la Confederación Argentina, Buenos Aires, 1857; Primer Censo General de la Nación, Buenos Aires, 1869; Segundo Censo General de la Nación, Buenos Aires, 1895. También Blanca Sanchez Alonso, La inmigración española en Argentina. Siglos XIX y XX, Colombres, Archivo de Indianos-Ediciones Júcar, «Cruzar el charco, 2», 1992. Sobre la población en la provincia de Buenos Aires, Nicolás SANCHEZ-AlboRnOz, "Rural Population and Depopulation in the Province of Buenos Aires: 1869-1960)", en Paul DEPREZ, comp., (1970): Population and Economics, Winnipeg, University of Manitoba Press, 1970, pp. 315-334.
} 
Por su parte, el gaucho, habitante tradicional de espacios abiertos y pastor a caballo, poco a poco cayó víctima de la modernización agropecuaria y de la implantación del alambrado. Con razón, José Hernández podía escribir en 1872 que el gaucho, "al paso que avanzan las conquistas de la civilización, va perdiéndose por completo"2. Además, la sustitución del gauchaje por los recién llegados y su transformación y eventual desaparición resultaron inevitables, aunque el proceso fuera lento y se llevara a cabo a menudo en medio de amargos choques. El criollo de las pampas vio en el extranjero, en el así llamado gringo, un rival privilegiado, mientras que el inmigrante deseoso de triunfar percibió al gaucho como un obstáculo que era preciso combatir pues se interponía entre él y el sueño de bienestar económico y de acceso a la tierra. En este enfrentamiento unos y otros fueron víctimas de la modernización y de una economía que dependía de capitales y mercados internacionales. Desde el punto de vista social, como bien lo señalara Gino Germani en un estudio pionero, criollos y colonos europeos se vieron atrapados en un proceso inmigratorio que siguió las pautas de la concurrencia y no de la integración, de la suma de individualidades y no del tan mentado crisol migratorio ${ }^{3}$. Finalmente, para decirlo con un neologismo que hoy se impone velozmente, la etnicidad fue un factor dominante en este encuentro, no solo con sus acercamientos y asimilaciones, sino también con sus enfrentamientos culturales, sus antagónicas valoraciones de la realidad, su conflictiva sociabilidad, sus metas irreconciliables y el radical desconocimiento y rechazo mutuos ${ }^{4}$.

2 Carta a José Zoilo Miguens reproducida por E. F. Tiscornia en su edición crítica del Martín Fierro, José HeRnANDEZ, Martín Fierro, con introducción, notas y vocabulario de Eleuterio F. Tiscornia, Buenos Aires, Losada, «Biblioteca clásica y contemporánea» $\left[1^{\mathrm{a}} \mathrm{ed}\right.$.: 1939], 1973, p. 21.

3 Gino Germani, Política y sociedad de una época de transición, Buenos Aires, Paidós, 1968, p. 252. Haydée GoROSTEGUI DE TORRES, Argentina. La organización nacional, Buenos Aires, Paidós, 1972. Otras obras de interés, aunque de carácter general, son las de y Ezequiel Gallo y CORTES CONDE, Roberto, Argentina. La república conservadora, Buenos Aires, Paidós, 1972.

4 Amplío aquí el sentido del término propuesto por Nathan GLACER, y Patrick MoYnihan, Ethnicity: Theory and Experience, Cambridge, Mass., Harvard University Press, 1975; véase también Russell A. KAZAL, "Revisiting Assimilation: The Rise, Fall, and Reappraisal of a Concept in American Ethnic History", en American Historical Review, abril, 1995, pp. 437-471.

R. I., $1998, \mathrm{n}^{\circ}{ }^{\circ} 214$ 


\section{XENOFOBIA Y VIOLENCIA: LA MASACRE DE TANDIL}

En este contexto de tensión entre recién llegados y nativos desplazados, al comenzar la década de 1870 tuvo lugar el acto más importante - pero no el único- que conocemos de violencia colectiva de la campiña tradicional contra los inmigrantes ${ }^{5}$. Al examinar este episodio, que tuvo lugar en Tandil, en el sur de la provincia de Buenos Aires, a la luz de una óptica nueva podemos entender las tensiones provocadas por la inmigración y su desenlace violento y milenarista como el resultado de un complejo fenómeno en el cual desempeñaron un papel importante la conflictividad social y económica y las tensiones de la etnicidad de dos actores en pugna. El paisano marginado y el extranjero emprendedor fueron presas de un sistema en el que ambos resultaron, a la vez, partícipes y víctimas.

Los acontecimientos de Tandil fueron seguidos con interés por la prensa de la época y sacudieron a los más diversos sectores de la sociedad bonaerense. Ecos de este interés aparecen en escritos del autor del Martin Fierro, José Hernández, cuya familia tenía tierras en esa zona de la provincia. Los hechos incluso cobraron carácter literario gracias a la pluma del hoy casi olvidado dramaturgo entrerriano Francisco F. Fernández (1841-1922), quien en 1872 escribió un "drama histórico, contemporáneo en 3 actos y 4 cuadros" sobre la matanza de extranjeros ocurrida en aquella ciudad el $1^{\circ}$ de enero de ese mismo año a manos de gauchos que, según el dramaturgo, habían sido fanatizados por un curandero o "manosanta", Gerónimo G. de Solané, cuyo apellido dio título al drama ${ }^{6}$. Poca atención volvió a

\footnotetext{
5 El periódico mexicano La Voz de España año II, núm. 214, $1^{\circ}$. IV, 1880, p. 2, comenta noticias aparecidas en El Globo, de Madrid, en las que se hace referencia a varios "asesinatos de españoles en la República Argentina", según reza el título del artículo. En él se indica que en la provincia de Entre Rios, en la región de Gualeguaychú, hubo a comienzos de ese año varios ataques contra españoles brutalmente muertos, incluyendo un niño y un estanciero; pero, según el articulista, sus autores no sólo gozaron de impunidad, sino que, incluso, en algún caso fueron públicamente recompensados con un cargo público. El crimen más violento parece haber sido contra tres españoles "macheteados" por gente del lugar. Agradezco a María Angeles Pintos de Bliss estos datos, incluyendo otros del mismo periódico sobre sucesos violentos ocurridos en México hacia la misma época.

6 Francisco F. FERNANDEZ, Solané, en Obras dramáticas, nueva edición con prólogo de Matías Calandrelli y Martín García Merou, s.l., Imprenta y Librería de Mayo [1 ${ }^{\mathrm{a}}$ ed.: 1877], 1881. Sobre este autor, véanse Ricardo RoJAS, Un dramaturgo olvidado, don Francisco Fernández y sus "Obras dramáticas", Buenos Aires, Facultad de Filosofía y Letras, Instituto de Literatura Argentina, «Sección de crítica, 1», 1923, y una breve nota sobre el
} 
recibir este episodio, hasta que en este siglo Antonio G. del Valle dedicara varias páginas de sus voluminosas memorias, Recordando el pasado (1926, tomo II), a la relación de los hechos, y Jan Fugl, un colono danés radicado en Tandil, recordara en Abriendo surcos: 1811-19007 los acontecimientos de los que él mismo había sido testigo. Más recientemente, otros investigadores han dedicado nuevas páginas a este tema. Uno de ellos, Ricardo Rodríguez Molas, en su Historia social del gaucho ${ }^{8}$ se apoya en la literatura ya existente y, de acuerdo con Fugl, sostiene que los grandes estancieros criollos y la Iglesia manipularon al gauchaje para frenar la inmigración que veían contraria a sus propios intereses ganaderos. Esta tesis había sido apuntada en 1967 por Juan Carlos Torre quien, en un breve pero sugerente artículo, explica este excepcional acto de milenarismo argentino como el resultado de las complejas circunstancias económicas y sociales que regían la expansión de la frontera, y la consiguiente transformación de la campiña bonaerense. Nuevas aportaciones documentales se encuentran en dos libros de Hugo Nario (1976; 1983), y una exposición de los hechos con base en algunos de estos autores aparece en Richard W. Slatta ${ }^{9}$. Si bien estas contribuciones siguen vigentes, quisiera en estas páginas volver sobre un análisis que realicé en 1978 y ampliarlo, en función de la complejidad que presentan los procesos migratorios que, como los de las campiñas bonaerenses, están marcados por etnicidades en conflicto y por intereses encontrados que se entrelazan y contraponen en diversos niveles culturales, sociales y económicos. Antes de proseguir, no está de más aclarar que la etnicidad no sólo implica asimilaciones e integraciones, como tradicionalmente se ha entendido ${ }^{10}$, sino también resistencias subjetivas, así como choques materiales y políticos que radican en el desconocimiento mutuo y en el rechazo irreconciliable del otro. Es también evidente que el conflicto entre etnicidades, que podemos observar con tanta nitidez en el caso de Tandil, no es exclu-

\footnotetext{
drama, en Roberto F. Giusti, "Los asesinatos de Tandil", Imago Mundi, 3 (marzo), 1954, pp. 69-70.

7 Juan FugL, Abriendo surcos: 1811-1900, Buenos Aires, Hachette, 1959.

8 Ricardo RODRIGUEZ MolAS, Historia social del gaucho, Buenos Aires, Ediciones Marú, 1968.

9 Richard W. SlatTA, Gauchos and the Vanishing Frontier, Lincoln, University of Nebraska Press [1 ${ }^{\mathrm{a}}$ ed.: 1983], 1993.

10 KAZAL, [4], analiza el concepto de la historiografía de los Estados Unidos.
} 
sivo de este episodio, ni de esta región sudamericana, sino que se reproduce en otros puntos del continente -desde las pampas hasta el Río Bravo-, aunque hasta ahora no hayan sido casi estudiados ${ }^{11}$.

Ante todo veamos los hechos. La acción se fraguó a lo largo de 1871 bajo el influjo de Solané, conocido como «Tata Dios» y reputado como curandero milagroso entre el gauchaje pobre de la zona. Por lo que sabemos, este personaje fue partidario del caudillo federalista Ricardo López Jordán, al que siguió en sus alzamientos en las provincias de Entre Ríos y Santa Fe. Después del triunfo político de Sarmiento y de la derrota del jordanismo, Solané se trasladó a la provincia de Buenos Aires y se instaló en la ciudad de Azul. Al poco tiempo, a raíz de dificultades con las autoridades locales, se volvió a mudar, esta vez a la cercana población de Tandil. Esta ciudad, fundada en 1823, contaba al cabo de unos escasos cincuenta años de existencia con cerca de 5.000 habitantes, divididos entre el casco urbano y la campiña, de los cuales un $15 \%$ eran extranjeros, en su mayoría españoles, franceses e italianos.

En Tandil, Solané afirmó su fama de curandero milagroso o manosanta, y con la ayuda de varios seguidores - "discípulos" o "santos"- organizó a los gauchos de la zona en una montonera que lo veneraba como a un mesías. En sus profecías de iluminado, el curandero expresaba una visión simple: acabar con los "extranjeros francmasones", según la conocida fórmula que había sido lanzada ya por Pío IX y la Iglesia romana desde el púlpito y que fue recogida por sectores tradicionalistas católicos en diversos lugares, reinterpretándola según cada contexto particular. En el caso de la montonera de Tandil, el sentido era claro y no se podía referir más que a los inmigrantes extranjeros y a los políticos liberales en la Capital —algunos, en efecto, masones, o considerados como tales, que pugnaban por la inmigración como un mecanismo para instrumentar la modernidad y el cambio. Según el imaginario de una religiosidad primitiva trasmitido por el manosanta, el exterminio de los inmigrantes causaría un cataclismo y la ciudad de Tandil se hundiría en la tierra; en su lugar surgiría un nuevo pueblo donde los elegidos - los gauchos "que

11 Véase Leticia GAMBOA OJEDA, "De «indios» y «gachupines». Las fobias entre empleados españoles y obreros mexicanos en la industria textil de Puebla (del Porfiriato y a la post-revolución)", Ponencia leída en el "Coloquio Internacional: La presencia española en Puebla, siglos XVI a XX", Universidad Autónoma de Puebla-Instituto de Ciencias Sociales y Humanidades, noviembre, 1995, (en prensa) y nota 5, supra. 
hubieran derramado sangre de extranjeros enemigos de la religión"- vivirían colmados de riquezas y felicidad. En su visión apocalíptica, el milagro se realizaría en cuanto los fieles, encabezados por los "santos", exterminaran a los forasteros; en recompensa, un huracán de fuego y torrentes de agua arrasarían la ciudad y de sus cenizas renacería en la Piedra Movediza un mundo nuevo ${ }^{12}$.

La matanza se planeó para el año nuevo y se llevó a cabo entre la madrugada del $1^{\circ}$ y el 2 de Enero de 1872 al grito de " $¡ V i v a$ la religión! ¡Viva la república! ¡Mueran los gringos y masones!” Los gauchos, que no eran más de cincuenta, iban armados con lanzas de caña o tacuaras, fusiles y cuchillos, y llevaban como divisa la cinta punzó, el distintivo federalista y antiporteño. Como resultado de la expedición redentora murieron treinta y seis personas, de los cuales cinco eran argentinos nativos. El resto en su mayoría eran colonos y trabajadores agrícolas vascos y franceses contratados por los terratenientes locales para alambrar los campos de la zona, que habían sido tierras ganadas por los indios al comenzar la década.

Además de estos muertos, la montonera también pasó a cuchillo a un organillero italiano y a una cuadrilla de peones vascos que esperaban en la plaza de las Carretas. De allí los gauchos se dirigieron a la estancia de un agricultor inglés, Willian Thompson, donde mataron a parientes y trabajadores. Luego, los iluminados continuaron su paso hacia la tienda de ramos generales del comerciante vasco francés Jean Chapar donde degollaron a varios hombres, mujeres y niños, dieciocho en total. En un acto característico de los motines tradicionales de muchedumbres enardecidas en sociedades preindustriales, la montonera quemó los libros de cuentas de la tienda con el afán ritual y real de cancelar sus eternas deudas impagables. Finalmente, al anochecer del día 2 acampó sin dificultad en las tierras de Ramón Santamarina, uno de los mayores estancieros de la zona, quien se hallaba ausente.

A la madrugada siguiente una tropa improvisada integrada por guardias y vecinos de Tandil atacó a los gauchos y, después de matar a varios, tomó a unos cuantos prisioneros mientras que los demás

\footnotetext{
12 Alegato del abogado defensor, Martín Aguirre, el 26 de febrero de 1872, durante el proceso, en Antonio G. del VAlle, Recordando el pasado.Campañas por la civilización, s.l., s.e., 2 tomos, (s.f. [1926])., II, pp. 572, ss. y Luis BAUDIZZONE, "Textos y documentos para la historia de la cultura. Los asesinatos de Tandil", Imago Mundi, 2 (diciembre), 1953, pp. 81-83.
}

R. I., $1998, \mathrm{n}^{\circ} 214$ 
se dispersaron. Entre los apresados estaba Gerónimo de Solané, quien se negó a prestar declaración mientras no fuera ante el juez de paz, señor Juan A. Figueroa, precisamente uno de los grandes terratenientes del partido de Tandil, a quienes muchos colonos creían protector de Tata Dios y quien se había manifestado como partidario decidido de limitar la colonización de las nuevas tierras y reducir la inmigración extranjera ${ }^{13}$. En vista de las dificultades para lograr la confesión del manosanta, finalmente se decidió pedir el envío de un juez de la capital. Sin embargo, poco antes de su llegada, en la madrugada del 6 de enero, Solané fue asesinado en su celda, acribillado a balazos por desconocidos. Este crimen frustró la posibilidad de descubrir si existían otros móviles, fuera de los milenaristas, que pudieron haber impulsado a los "santos" a la violencia y de lograr ninguna información adicional sobre posibles protectores o encubridores del cabecilla. La sentencia final condenó a tres de los más allegados a morir fusilados en la plaza e impuso largas penas de prisión a los demás implicados, pero en el proceso judicial nunca se pudieron probar las supuestas complicidades e intereses ocultos de políticos y estancieros de la región o de simpatizantes jordanistas.

\section{III. ¿MILENARISMO, ETNICIDAD, LUCHA SOCIAL?}

Aunque narrados aquí de modo esquemático, estos hechos plantean problemas significativos respecto de los autores y las situaciones de este conflicto, y nos permiten adelantar algunas hipótesis generales. En primer término, resaltan los rasgos tradicionales de este gauchaje cuyo imaginario religioso y social responde a las influencias mesiánicas de curanderos y de visiones milenaristas y apocalípticas. Por un lado, la montonera crédula acepta ingenuamente la ecuación que identifica la muerte y destrucción de quienes son percibidos simultáneamente como opresores y pecadores con el ejercicio de una voluntad suprema que ha elegido a los gauchos como vehículo de castigo divino. Por otro lado, este gauchaje identifica la destrucción y el incendio de las propiedades ajenas con la purificación y la recreación de un mundo nuevo como recompensa de los

13 Hugo NARIO, Tata Dios, el mesías de la última montonera, Buenos Aires, Plus Ultra, 1976; Los crímenes de Tandil, Buenos Aires, Centro Editor de América Latina, 1983. 
justos y los santos. Más allá de este conjunto de símbolos y de representaciones y de esta íntima visión milenaria, debemos también tener en cuenta los elementos materiales que enmarcan los hechos en una complejidad histórica de la cual el gaucho es solo una de las partes. La montonera de divisa punzó, cuyo líder tal vez mantuviera aún relaciones con los partidarios federalistas y antibonaerenses de Ricardo López Jordán, reflejaba cruda pero eficazmente la oposición entre el campo criollo y tradicional y la cosmopolita y pujante ciudad de Buenos Aires. Esto sucedía en un momento en que la radicación de grandes masas de agricultores extranjeros, la instalación de alambrados y el cruce de ganado criollo cimarrón con reproductores importados, contribuían a convertir la ganadería en sedentaria y hacían cada vez más difícil la vida del gaucho nómada en espacios sin límites.

Este antagonismo no se redujo al peón y al colono inmigrante, sino que incluyó a los pequeños comerciantes extranjeros, especialmente buhoneros, pulperos o tenderos, que además de ropa, aperos, yerba mate y víveres, despachaban tabaco y alcohol y actuaban como prestamistas, a través del empeño de prendas; con ellos el proletariado agrícola se encontraba también endeudado. En el Martín Fierro, Hernández pone en boca de su personaje la descripción del típico "pulpero habilidoso", abusivo y usurero, que "nos tenía apuntaos a todos / con más cuentas que un rosario" (I 685-726). En Tandil, la quema de los libros de cuentas en la tienda del pulpero extranjero Chapar fue, si se quiere, un típico acto de resistencia primitiva pero también es evidente que estaba directamente dirigida contra los instrumentos que perpetuaban las deudas y la pobreza. Así, para el gauchaje criollo, la doble imagen del gringo y del explotador quedaba en muchas ocasiones superpuesta en una elemental xenofobia. No cabe duda de que para los actores de la revuelta, la visión milenarista opacaba la conciencia del resentimiento explícito contra las realidades económicas y sociales. Asimismo, también es evidente que la religiosidad mesiánica permitía canalizar la cólera popular, convertida en agente de Dios, en una esquemática pero totalizadora polarización entre lo diabólico - es decir, los elementos de opresión y miseria en la sociedad presente, satanizados a través de su identificación con el extranjero francmasón-, y lo divino - es decir, el mundo ideal de bienestar y abundancia para los gauchos elegidos.

Por otra parte, no es aventurado sospechar que los terratenientes y políticos locales, temerosos de ser desplazados por los intereses 
financieros porteños y extranjeros y por los grupos liberales de la capital, utilizaran al paisanaje descontento en beneficio propio. La coyuntura se vio favorecida por la aparición del carismático Solané; éste, que estaba familiarizado con la rebelión de López Jordán contra Buenos Aires, se erigió fácilmente en defensor del interior criollo y cabeza de la montonera. Incluso el epíteto de francmasones, lanzado contra los extranjeros en Tandil, no sólo recoge el eco de la política antiliberal de Pío IX, sino que refleja las tensiones civiles y políticas del país, ya que muchos miembros del gobierno nacional, empezando por el propio presidente Sarmiento, pertenecían a la francmasonería. En la Argentina, el epíteto no definió únicamente a los liberales, como sucedió en otros paises, sino también a los habitantes de Buenos Aires, y así se incorporó al lenguaje político de los enemigos de la ciudad capital y puerto.

Finalmente, si bien los elementos de una religiosidad primitiva y los intereses materiales, sociales y políticos en pugna resultan factores evidentes en el desarrollo del conflicto, el choque de dos culturas en encuentro, de etnicidades a menudo irreconciliables, fueron igualmente detonantes de los acontecimientos. Sin embargo, lo más significativo es que la complejidad de la etnicidad rebasó a los actores inmediatos del drama y abarcó de manera amplia a la sociedad argentina. En efecto, los rechazos y prejuicios fueron recíprocos y plurales, e incluyeron no sólo a gauchos y trabajadores sino también a terratenientes del interior y comerciantes del litoral, a los sectores políticos más tradicionales y a los liberales que gobernaban, legislaban y abrían las fronteras del comercio, las finanzas y las ideologías a un mundo exterior que arrasaba irremediablemente con una Argentina que hasta el último tercio del siglo XIX se recluía aún en tradiciones y estructuras todavía de antaño. Durante muchas décadas el pluralismo, la convivencia, la exogamia, la integración, el aprecio mutuo se enfrentaron a la homogeneidad, la desconfianza, el prejuicio, la discriminación, el insularismo, el desprecio recíproco. En síntesis, de estas variadas enumeraciones contrapuestas podemos derivar el complejo entramado en el que se insertó y desarrolló la etnicidad conflictiva de los inmigrantes y los paisanos de las pampas. 


\section{LAS REDES DEL CONFLICTO}

El estudio de los acontecimientos de Tandil nos lleva finalmente al análisis de los grupos implicados, de sus interrelaciones y de los diversos niveles de tensión. A primera vista se advierten en el conflicto dos grandes sectores: el criollo y el extranjero; pero, un enfoque más minucioso nos revela que ni uno ni otro eran homogéneos y que en ambos intervenían factores variados y a menudo contradictorios.

Los criollos eran tanto los terratenientes locales, temerosos del poderío y la expansión de los intereses porteños y extranjeros, cuanto los gauchos, que dependían directamente de la oligarquía de la zona. Los primeros no sólo poseían la tierra y monopolizaban las fuentes de empleo rural, sino que controlaban los instrumentos de poder político local - jueces, concejales-y del poder financiero de la región - contratistas, comerciantes, prestamistas. Por su parte, el paisano nativo vivía atado al campo y atrapado a la red de intereses y poder de los estancieros y sus aliados - lo que en boca de uno de los personajes del Martín Fierro, se resume en dos versos: "que aquí el nacer en estancia / es como una maldición" (II, 3711-3712).

Aparentemente enfrentado al sector criollo estaba el extranjero, a su vez también dividido internamente. Por un lado, financieros y comerciantes de origen europeo compartían el poder económico con las oligarquías nativas, mientras el gringo, inmigrante proletario, desempeñaba a menudo, sin siquiera sospecharlo, el papel de punta de lanza de intereses que, ante todo, beneficiaban a inversionistas de aquí y de allá. En general, los inmigrantes formaban parte de un mercado consumidor y, a menudo, con sus ahorros y remesas al terruño contribuían en cierta medida al fomento de la banca y del capital financiero de sus países de origen. Por otra parte, el gringo se relacionaba con la población criolla en una doble vinculación. Por un lado, dada su condición de asalariado o colono, dependía directamente de los terratenientes, quienes, a la vez que los contrataban por sus mayores capacidades agropecuarias, se revelaban temerosos del peligro que para el orden tradicional representaba el peso numérico de los extranjeros. Por otro lado, los extranjeros competían y se enfrentaban con el paisanaje, la más de las veces resentido por el empuje de ese aluvión inmigratorio que lo amenazaba en sus ingresos, lo desplazaba de su mundo y chocaba con sus tradiciones y cultura.

R. I., $1998, \mathrm{n}^{\circ} 214$ 
Al mismo tiempo que los conflictos se perfilaban a lo largo de una clara línea divisoria entre nativos y extranjeros, también debemos tener presente las diferencias existentes dentro de cada grupo socio-económico, que se traducían en las continuas fricciones de los poderosos del Viejo Mundo con los del Nuevo, por un lado, y entre los oprimidos de ambos continentes, por otro. Pero la división no era solo geográfica; también los antagonismos sociales marcaban una frontera de conflictos: los capitalistas de ultramar y los marginados europeos trasplantaron a América su secular lucha de clases, en tanto que los hacendados ricos y sus peones criollos siguieron enfrentándose como lo habían hecho durante décadas, desde las guerras de Independencia ${ }^{14}$.

Sin embargo, al devanar la madeja del conflicto podemos apreciar que éste tampoco se limitaba a una lucha social vertical entre poderosos financieros y gringos pobres, entre terratenientes y gauchos. La trama se entreteje con etnicidades enfrentadas y consiguientes xenofobias, cuyo complejo imaginario milenarista no oculta la profunda oposición de clases. Los intereses de capitalistas acabaron por imponerse sobre los marginados criollos y se sintetizaban en una fórmula exitosa: civilización contra barbarie; por su parte, los terratenientes locales consolidaron sus privilegios y poderes contra la ambición de tierras y de movilidad social del gringo pobre.

$$
* * *
$$

En síntesis, al comenzar la década de 1870, una Argentina en pleno comienzo de su vertiginosa expansión y desarrollo materiales y en la alborada de un espectacular crecimiento inmigratorio nos descubre la compleja red de tensiones profundas entre dos mundos en apariencia irreconciliables. Estas dos realidades, con sus difíciles mezclas de tradición y modernidad, de tensión entre los poderosos y los humildes, se encuentran, entrecruzan y enfrentan. Los choques son múltiples: el extranjero contra el criollo, el pastor trashumante contra el campesino sedentario, el campo abierto cercado por los alambrados, las nuevas técnicas desplazando a las viejas costumbres, las antiguas sociabilidades amenazadas por la nuevas competencias

14 Clara E. LIDA, "Socialismo y sindicalismo en Latinoamérica: de la Independencia a la Segunda Guerra", en Op. Cit. (Universidad de Puerto Rico), 3, 1987-1988, pp. 10-23. 
sociales, los imaginarios arcaicos en pugna con las nuevas utopías. Sobre este entramado cambiante se tejen etnicidades adversas, con sus xenofobias recíprocas y culturas opuestas, y, como corolario, en él se urden también los conflictos inherentes de una sociedad vertiginosamente cambiante pero piramidal, desde cuya base nuestros personajes centrales, los gauchos marginados y los inmigrantes, podrían dificilmente ascender.

En estas páginas hemos querido mostrar cómo estos elementos plurales se enlazan entre sí al producirse la rebelión de los gauchos de Tandil contra los colonos extranjeros y cómo, a pesar de su carácter primitivo y milenario, nos es posible adentrarnos en la complejidad de un fenómeno colectivo que hasta ahora se había presentado como un simple acto de rebeldía primitiva e irracional. En el estudio del caso hemos pretendido forjar un análisis que nos permita iluminar mejor las causas de este tipo de violencia social que situamos en el vértice que conforman las diversas facetas de una Argentina lanzada a la modernidad, tales como la inmigración masiva, los cambios sociales, las etnicidades en conflicto y las transformaciones económicas y, desde luego, políticas.

Milenarism and xenophobia combined in the gaucho revolt of Tandil (Argentina), in 1872. At the origins of this movement lie the regional and provincial oposition against the centralism of Buenos Aires, the enclosure of lands which menaced the traditional gaucho itinerancy, the growth of agro-exporting capitalism at the expense of internal markets and commerce, and the decisive growth of European massive inmigration. Prompted by the social and provincial power-groups, the gauchos imagined the emergence of a millenarian utopia only in the Argentine Pampas only after the violent extermination of all foreigners, perceived as major cause for the collapse of their traditional society. 